\title{
Sex, race, and psychomotor reminiscence
}

\author{
R. B. PAYNE \\ University of Georgia, Athens, Georgia 30602 \\ and \\ IRA D. TURKAT \\ Vanderbilt University, Nashville, Tennessee 37203
}

\begin{abstract}
This study extended the search for boundary conditions of the well-known female dominance in psychomotor reminiscence by comparing subjects of Caucasoid and Negroid ancestries. Apportioned equally among the four combinations of sex and race, 72 subjects engaged in alternating periods of massed practice and rest on a mirror tracking task. Females of both races reminisced more than their male counterparts, but race contributed virtually nothing to the variance of reminiscence. However, Caucasoid subjects maintained an essentially constant margin of task proficiency over Negroid subjects across the practice sequence. Various hypotheses concerning this effect are discussed.
\end{abstract}

Although the problem of psychomotor reminiscence no longer generates as much excitement as it once did, certain aspects of it continue to be pursued with considerable zeal. Among these is the sex difference in the magnitude of reminiscence. Using a rotary pursuit task as the test vehicle, Buxton and Grant (1939) were perhaps the first to observe that young adult Caucasoid females reminisced more than their male counterparts. Subsequent studies have confirmed this phenomenon many times and have explored its relationship to a variety of task, procedural, and organismic variables. The thrust of these studies has been twofold: first, to ascertain the boundary conditions of the sex difference, and second, to relate the difference to prevailing theoretical conceptions of reminiscence.

With regard to boundary conditions, studies reported thus far have been limited to task, age, and practice variables. For example, Huang and Payne (1975) replicated the original observation on rotary pursuit and extended it to a mirror tracking task, but they found no sex difference in reminiscence on an inverted-alphabet printing task. Comparable results on alphabet printing were found in prepubescent children, although significant amounts of reminiscence did occur (Zegiob \& Payne, 1977). These findings suggest, as Noble (1978) has noted, that the sex difference is probably confined to tasks that require continuous monitoring and responding vis-á-vis those that call for intermittent, discrete responding. For those tasks in which the sex effect has appeared, which sex reminisces more depends upon the developmental status of the subjects. Whereas young adult females reminisce more than young adult males (Buxton \& Grant, 1939; Huang \& Payne, 1975), prepubescent females

Requests for reprints should be sent to R. B. Payne, Department of Psychology, University of Georgia, Athens, Georgia 30602. reminisce less than prepubescent males(Ammons, Alprin, \& Ammons, 1955; Horn, 1975; Zegiob \& Payne, 1977). The reversal of sex dominance in reminiscence across pubertal years is paralleled by observations of the relative gains of the sexes in distributed practice experiments (McCaffrey \& Payne, 1977; Resick \& Payne, 1978). The young adult sex effect has also appeared routinely in studies designed to investigate the effect of interpolated-task practice on main-task reminiscence (Coppage \& Payne, 1981; Hsu \& Payne, 1979). Thus, female dominance in reminiscence seems limited to a particular class of tasks and to some unknown range of postpubescent ages, but within these conditions it is remarkably robust across a variety of practice arrangements.

Female dominance in reminiscence lends itself readily to interpretation in terms of Hull's (1943) concept of reactive inhibition (IR). On this hypothesis, as elaborated elsewhere (Coppage \& Payne, 1981; McBride \& Payne, 1979), females reminisce more than males do because they accumulate more IR per unit of prerest practice. If this is so, and if the IR concept is fundamentally credible, one must find that (1) with the amount of prerest practice held constant, the amount of reminiscence will increase for both sexes as a negatively accelerated function of the length of the rest period, (2) the asymptotic level of this function will be higher for females than for males, and (3) the slope of the prerest performance curve will be less for females than for males. These expectations have been confirmed (McBride \& Payne, 1979). On the same hypothesis it was also predicted that the well-known male dominance in rotary pursuit performance would disappear under highly distributed practice conditions. This, too, has been confirmed (McBride \& Payne, 1980). Moreover, there is persuasive evidence that the greater female proclivity for generating $I_{R}$ may be related to estrogenic events of the menstrual cycle 
(Lamson-McBride \& Payne, 1981; Wells \& Payne, 1979).

Perhaps because of the limited sampling opportunities that prevail at most experimental sites, studies of the generality of reminiscence tendencies across races are not available in the psychomotor literature. The present study sought to close this gap to some degree by comparing subjects of Caucasoid and Negroid ancestries, particularly with reference to the question of female dominance. Although there were no firm grounds for expecting an interaction of sex and race effects, Noble (1968) reported studies in which Caucasoid children outperformed Negroid children on rotary pursuit, increasingly so as practice proceeded. Of course, the interaction of practice and race effects might have resulted from racial differences in learning ability, but it lends itself equally well to interpretation in terms of differential accumulation of IR. In fact, Jensen (1972) suggested that the race difference per se, quite apart from the interaction, might be explained in this way. If it is the case that Negroid subjects accumulate more $I_{R}$ per unit of prerest practice than Caucasoid subjects do, one should find a race effect in reminiscence tendencies, with perhaps a somewhat different distribution of these tendencies among the Negroid sexes.

\section{METHOD}

\section{Subjects}

The experimental sample consisted of 72 subjects apportioned equally among the four combinations of race and sex. They were drawn by consent from introductory psychology classes at the University of Georgia, and they were given course credit points for participation. Their mean age was $\mathbf{1 9 . 6}$ years, and there were no significant age differences among the subgroups. All were right-handed and visually competent.

\section{Task}

The experimental task required subjects to use mirror vision in order to track a small silver target as it moved clockwise at $1 \mathrm{rpm}$ through a narrow star-shaped pathway. Subjects were instructed to keep the tracking stylus on target as long as possible and to avoid touching the sides of the pathway. Time on target was recorded to the nearest $.01 \mathrm{sec}$ for each minute of practice.

\section{Procedure}

After instruction and demonstration, all subjects executed a sequence consisting of 3 min massed practice (Block 1, Trials 1-3), 3 min rest, 3 min massed practice (Block 2, Trials 4-6), 3 min rest, and 3 min massed practice (Block 3, Trials 7-9). Debriefing concluded the testing session.

\section{RESULTS}

Experimental treatment effects were measured in terms of (1) reminiscence scores and (2) performance scores across the three blocks of massed trials.

\section{Reminiscence}

The interpolation of two rest periods in the practice sequence permitted the derivation of two reminiscence scores for each subject. The first was found by subtracting the score on Trial 3 from that on Trial 4 , and the second was found by subtracting the score on Trial 6 from that on Trial 7. The 144 scores were subjected to a mixed-model variance analysis in which race and sex provided the main between-subjects effects and reminiscence periods provided the main within-subjects effect. As all previous adult studies of the sex difference in reminiscence have shown, females reminisced more than males $[F(1,68)=4.28, p<.05]$. Mean reminiscence was $6.55 \mathrm{sec}$ for females and $4.55 \mathrm{sec}$ for males. Since no other variances were significant, one can conclude that the two racial samples reminisced alike and that the sex effect was characteristic of both samples.

\section{Performance}

The analysis of performance scores was undertaken primarily to look for evidence of interaction between sex and practice effects, but in view of Noble's (1968) results, there was also a strong interest in the race effect and its possible interaction with the practice effect. With regard to the former objective, it will be recalled that Hull's (1943) concept of IR, when employed as an explanation of female dominance in reminiscence, requires an interaction of sex and practice effects in which females gain less per unit of prerest practice than males do. Given the observed generality of female dominance in reminiscence across races, one should also find evidence of the generality of the sex-practice interaction across races. Accordingly, the 648 performance scores were subjected to a mixed-model variance analysis in which race and sex provided the main between-subjects effects and trial blocks and trials within blocks provided the main within-subjects effects. Concordant with earlier results (McBride \& Payne, 1979), the overall sex effect was not significant $[F(1,68)=2.67, p>.05]$, but the re was a significant interaction of the sex effect with the trials-within-blocks effect $[\mathrm{F}(2,136)=8.78, \mathrm{p}<.001]$. Moreover, the interaction was independent of the race effect and the block effect, as shown by the negligible Sex by Trial by Race and Sex by Trial by Block interactions ( $F<1$ in both instances). This outcome can be more fully appreciated by reference to Figure 1,

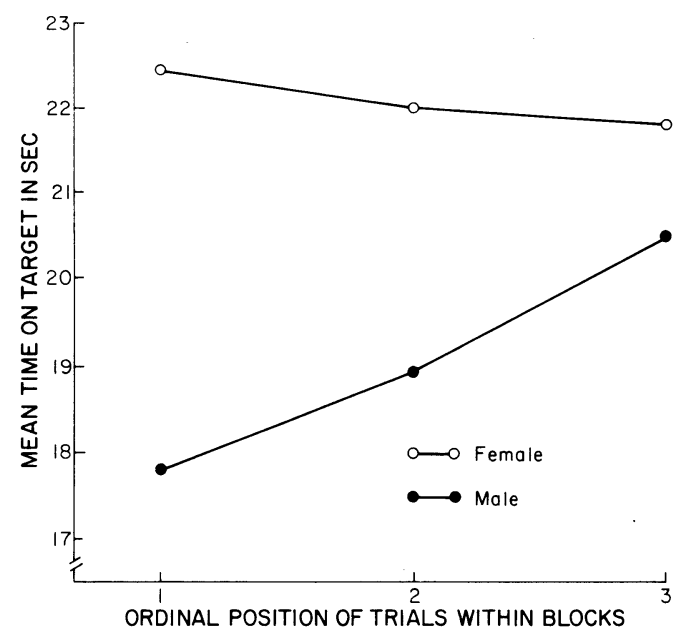

Figure 1. The sex difference in performance as a function of ordinal position of trials within practice blocks. 


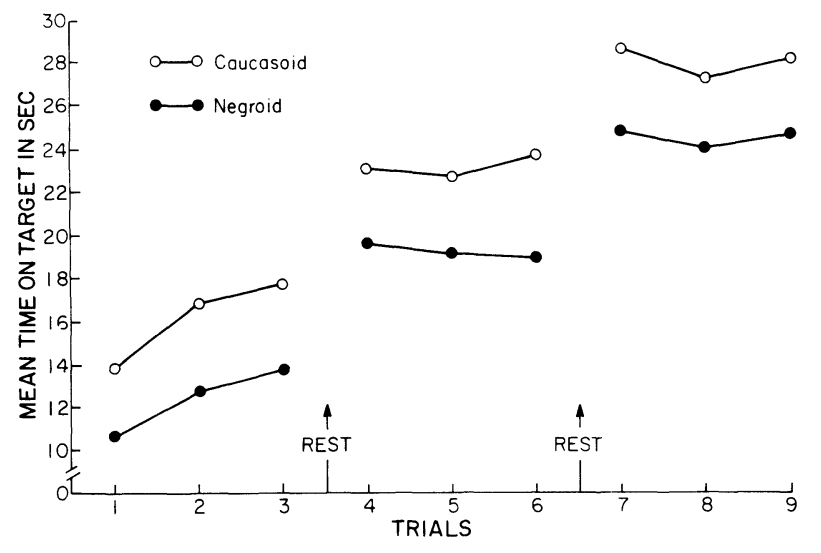

Figure 2. Performance trends as functions of race.

which depicts the sex difference as a function of the ordinal position of trials within blocks.

With regard to the race effect, the overall Caucasoid mean time on target per trial $(22.46 \mathrm{sec})$ was significantly higher than the Negroid mean $(18.7 \mathrm{sec})[\mathrm{F}(1,68)=4.23$, $\mathrm{p}<.05]$. Inasmuch as this effect was orthogonal to all other effects produced by the experimental procedures, one may conclude that the Negroid subjects began the task with some sort of handicap but maintained essentially the same rate of progress as Caucasoid subjects did throughout the sequence of practice and rest conditions. Figure 2 depicts performance as a function of race and practice.

\section{DISCUSSION}

The foregoing operations produced two outcomes worthy of further comment. First, it is clear that the young adult sex effect on reminiscence found in Caucasoid subjects can be safely generalized to subjects of Negroid ancestry, and the presumption is thereby strengthened that this is true of other races as well. It is also clear from the race-independent interaction of sex and practice effects that the $I_{R}$ interpretation of the sex difference in reminiscence applies equally to both races, and perhaps to other races as well.

The second noteworthy outcome was the Caucasoid dominance in performance level. Although the cause of this dominance cannot be specified at the present time, several alternatives can be eliminated forthwith on the evidence from this and other investigations. For one, the evidence of dominance on the mirror tracking task cannot be regarded as evidence for a general Caucasoid advantage in motor skills, for, as Noble (1978) has pointed out, no race has been shown to be consistently superior across a wide spectrum of psychomotor abilities. For another, the race effect cannot be ascribed to differential accumulation of $I_{R}$, as Jensen (1972) hypothesized, for the races reminisced essentially alike and there was no significant interaction of race and practice effects. On the same evidence, the race effect cannot be ascribed to differential learning rate, for the race curves were essentially parallel throughout the sequence of practice blocks and trials within blocks.

Whatever the causal factor was, it exerted a constant effect across the practice sequence. Given this constraint of constancy of effect, what are the viable alternatives? For one, the racial samples may not have been equally motivated to participate in the study. Some of the Negroid subjects expressed mild reservations about participating in the experiment because they were apprehensive about the prospect of invidious comparisons with Caucasoid subjects. Whether this attitude translates into low enthusiasm (undermotivation) or test anxiety (overmotivation), the adverse effect upon performance seems likely to be about the same. For another, the racial samples may have entered the task with different strengths of some of the component skills that the task comprises, notably those based on visual feedback from reflecting surfaces. No data could be found concerning such background experiences. Finally, one might appeal to some sort of differential hereditary predisposition to cope with the requirements of the task. This hypothesis is so vague as to seem almost frivolous, for nothing is known about the factorial composition of the task or the heritability of component abilities required for its performance. Nonetheless, Noble (1978) has provided strong evidence for the role of heritability in racial differences on certain psychomotor tasks, and for this and kindred reasons, the hypothesis remains viable.

\section{REFERENCES}

Ammons, R. B., Alprin, S. I., \& Ammons, C. H. Rotary pursuit performance as related to sex and age of pre-adult subjects. Journal of Experimental Psychology, 1955, 49, 127-133.

Buxton, C. E., \& Grant, D. A. Retroaction and gains in motor learning: II. Sex differences, and a further analysis of gains. Journal of Experimental Psychology, 1939, 25, 198-208.

Coppage, S. J., \& Payne, R. B. An experimental test of current theories of psychomotor reminiscence. Perceptual and Motor Skills, 1981, 52, 343-352.

HoRN, P. W. Pursuit rotor speed, sex differences, and reminiscence in young children. Journal of Psychology, 1975, 91, 81-85.

Hsu, S. H., \& PAYNE, R. B. Effector localization and transfer of reactive inhibition. Journal of Motor Behavior, 1979, 11, 153-158.

Huang, K. L., \& Payne, R. B. Individual and sex differences in reminiscence. Memory \& Cognition, 1975, 3, 252-256.

Hull, C. L. Principles of behavior. New York: Appleton-CenturyCrofts, 1943.

Jensen, A. R. Genetics and education. New York: Harper \& Row, 1972.

Lamson-McBride, E., \& Payne, R. B. Psychomotor reminiscence and the menstrual cycle. Bulletin of the Psychonomic Society, 1981, 17, 97-100.

McBride, D. K., \& PAYNe, R. B. Psychomotor reminiscence as a function of sex and length of rest period. Journal of Motor Behavior, 1979, 11, 59-64.

McBride, D. K., \& PAYNe, R. B. The sex difference in rotary pursuit performance: Aptitude or inhibition? Journal of Motor Behavior, 1980, 12, 270-280.

MCCAffrey, R. J., \& PAYNe, R. B. Interaction of sex and practice distribution effects. Bulletin of the Psychonomic Society, 1977, 10, 382-384.

NoBle, C. E. The learning of psychomotor skills. Annual Review of Psychology, 1968, 19, 203-250.

Noble, C. E. Age, race, and sex in the learning and performance of psychomotor skills. In R. T. Osborne, C. E. Noble, \& N. Weyl (Eds.), Human variation: The biopsychology of age, race, and sex. New York: Academic Press, 1978.

Resick, P. A., \& PAYNe, R. B. Sex and practice distribution effects in children. Bulletin of the Psychonomic Society, 1978, 11, 380-382.

Wells, K. C., \& PAYNe, R. B. Psychomotor reminiscence as a function of gonadal steroid hormone variation. Bulletin of the Psychonomic Society, 1979, 14, 197-200.

ZEg IOB, L., \& PAYNe, R. B. Reminiscence in children as a function of sex. Bulletin of the Psychonomic Society, 1977, 9, 173-175. 